\title{
Case report: Treatment of episiotomy scars according to the concept of Fascial Manipulation ${ }^{\circledR}$
}

\author{
(1) JAROSŁAW CIECHOMSKI ${ }^{1}$, (1) PAWEŁ MALICKI ${ }^{2}$ \\ 1Osteopathic and Rehabilitation Clinic, Poznań, Poland \\ 2 TERPA Clinic, Lublin, Poland
}

\section{ABSTRACT}

The widespread use of episiotomy contributes to pelvic floor muscle dysfunction and concomitant complaints. The biomechanical model of the Fascial Manipulation method addresses the consequences of episotomy. Ailments such as painful intercourse, dysuria, chronic pelvic pain can be successfully treated using the Fascial Manipulation model.

Keywords: Care of the scar tissue; chronic urogenital pain; dysuria; episiotomy; Fascial Manipulation; pelvic sensitization; pudendal nerve neuralgia

\section{INTRODUCTION}

This case study highlights the application of the Fascial Manipulation $^{\circledR}$ (FM) method to the treatment of episiotomy scars. It provides general information concerning episiotomy scars, and outlines an approach based on FM concepts, and provides useful suggestions about the care of the scar tissue. On the basis of evidence from this case study and literature in general the concluding remarks questions the ongoing use of episiotomies.

Episiotomy is the most commonly used surgical procedure despite the fact that its effectiveness has never been proven. On the contrary, research since the early 1980s provides new evidence of the harmfulness of this procedure.

Medical standards should be based on current, reliable and credible scientific research. This would give doctors and midwives confidence that what they are doing is best for their patients, based on the effectiveness of a given procedure. In the case of episiotomy, the procedure is still widely used, in spite of recommendations to the contrary.

The history of the episiotomy dates back to the $17^{\text {th }}$ century and the first use of forceps. The first mention of this procedure in obstetric literature appears at the beginning of the $19^{\text {th }}$ century. Canadian sociologist lan Graham, who studied the history of episiotomy in Anglo-Saxon countries, writes that the incision was initially treated distrustfully and as a last resort, even for fear of infection. One of the promoters of routine episiotomy was the influential American obstetrician Joseph De Lee. In 1913 he published the thesis that every delivery is a pathological process and requires surgical intervention. ${ }^{1-3}$ His suggested delivery method consisted of using anesthesia, making an extensive episiotomy and bringing out the baby with forceps. In the first half of the $20^{\text {th }}$ century, routine episiotomies gradually gained widespread acceptance; in the US in the 1930s and 40s; in Great 
Britain and other European countries in the 1950s and 60s. Until the 1980s, neither doctors, midwives, nor women questioned the need for routine incision in the perineum, though the benefits have never been proven.

In the 1980s, thanks to the popularization of evidence-based medicine and the emergence of movements promoting women-friendly obstetrics, the routine episiotomy was criticized. The World Health Organization (WHO) in the document "Childbirth is not a disease" recommended limiting the use of episiotomy because "there is no excuse for routine episiotomy". ${ }^{2}$ Currently, the recommendations of the WHO regarding the conduct of normal delivery states "There is no credible evidence that liberal or routine episiotomy has positive effects. Research clearly shows the opposite. In a number of normal deliveries, an episiotomy is justified, but it is recommended to limit the use of this procedure". ${ }^{1}$ Experts from the WHO state that it is justified to use an episiotomy in $5-20 \%$ of births. ${ }^{3}$ It is also noteworthy that The Cochrane Library, refers to the procedure as one whose harmfulness and lack of effectiveness have been proven beyond reasonable doubt. 4,5

The classification of perineal injuries during delivery (according to the International Classification of Diseases) provides the following guidelines,

First degree- rupture of the vagina and skin of the perineum without disturbing the pelvic floor muscles,

Second degree-pelvic floor rupture, perineal and vaginal muscles,

Third degree-rupture involving the external anal sphincter, Fourth degree-rupture involving the rectal mucosa.

These guidelines are outlined in brief and are referred to in the following case study and discussion.

\section{CASE REPORT}

Anna is a 30-year-old medical practitioner referred for physiotherapy on account of severe recurrent back pain of one month's duration, with pain severity rated as 6/10 on the VAS. Worsening of the pain occurs when she carries her six-month old baby, and during defecation when pain is rated as $3 / 10$ on the VAS. Anna had a natural delivery with an episiotomy. However, her backpain predates the birth by 14 years. Comorbidities that the patient complained about include: night teeth clenching and wearing braces for 19 years, dysmenorrhea for 15 years, (8/10 on VAS), morning feet pain since she was 13 years old (5/10 on VAS), and irritable bowel syndrome for three years. Based on the FM model, the treatment hypothesis considered the endocrine apparatus and the caput segment (head) as the most involved according to the chronology of symptoms and the FM principle that "old is gold"- referring to the chronology of symptoms.

\section{Treatment and results of the fascial manipulation concept}

Anna was provided with four sessions of FM and two sessions of scar mobilization. The first session was dedicated to the following points as shown in Figure 1 and Figure 2.

At the time of the second session she reported no back pain and being able to carry her baby without any problems, or with only mild discomfort (2/10 on VAS). There was no more discomfort

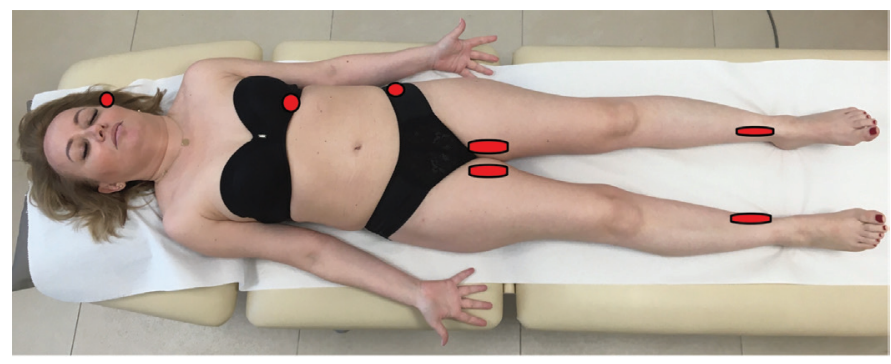

Figure 1. Anterior points. IRCP2 rt (head), IRTH It (chest), IRPV rt, (pelvis), qANMECX bi (thights), qANMETA3 bi, (calves)

during defecation. The therapist decided to continue the treatment started during first session and manipulate following points as shown in Figure 3.

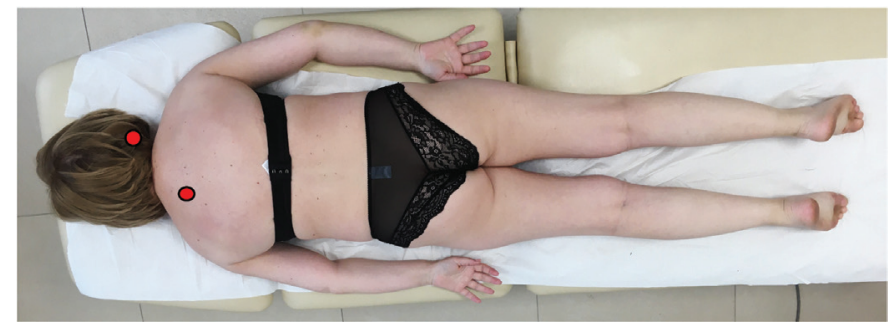

Figure 2. Photo of posterior points. ERCP3 rt (head), ERTH It (chest)

After two weeks patient reported full improvement in back pain (0/10 VAS) and also in morning feet pain (1/10 VAS). During the next two sessions mobilization of the episiotomy scar was performed and one week later she was provided training in automobilization of scar tissue. At the time of the third session of $\mathrm{FM}$, one month later she reported a significant improvement in dysmenorrhea (4/10 VAS). Anna still reported feeling bloated due to her irritable bowel syndrome (5/10 VAS). Palpatory verification highlighted points for manipulation as shown in Figure 4 and 5. The fourth session took place one month later, to verify any 
improvement in dysmenorrhea and other complaints of the patient. In the case of dysmenorrhea there was a further improvement (2/10 on VAS), now described as a feeling of discomfort, but no pain. As far as bloating was concerned, sensations decreased to the level of 3/10 on the VAS. In that case, after palpatory verification, therapist decided to manipulate the following points as shown in Figure 6 and Figure 7.

After these sessions Anna was asked to make a phone call in case of worsening of symptoms and pain. Two months after her last treatment a follow up phone call was made and she reported that there was no noticeable pain or any worsening of comorbidities. The same phone call was made after four, six, and eight months following treatment and there was no worsening of symptoms and pain reported by the patient.

The authors recommend the use of the FM method in the

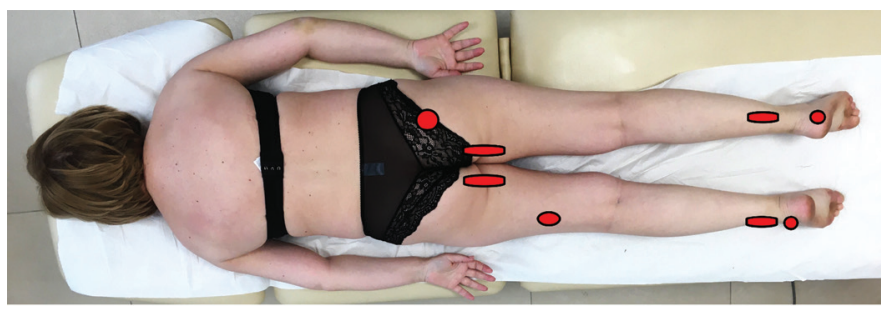

Figure 3. Photo of points treated during second session. qREMECX bi (thights), RELATA3 bi (calves), ERCX rt (m. piriformis), ERGE It (distal part of left thight), RELAPE2 rt, RELAPE1 It (foot)

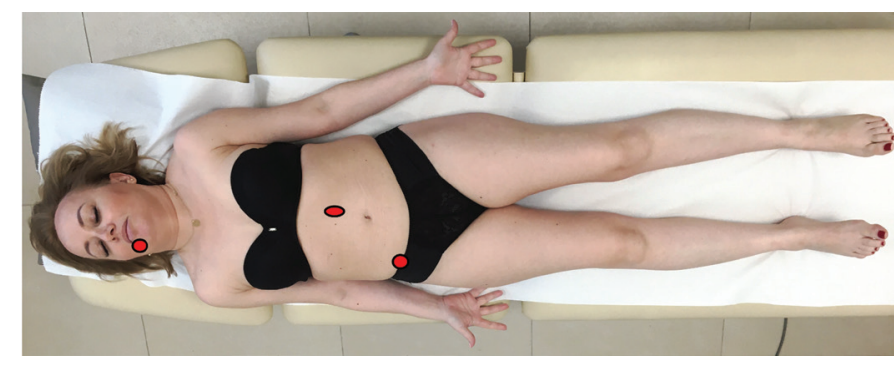

Figure 4. Photo of anterior points. ANMECP3 rt (head), ANMELU2 It (above umbilicus) ANPV rt (pelvis)

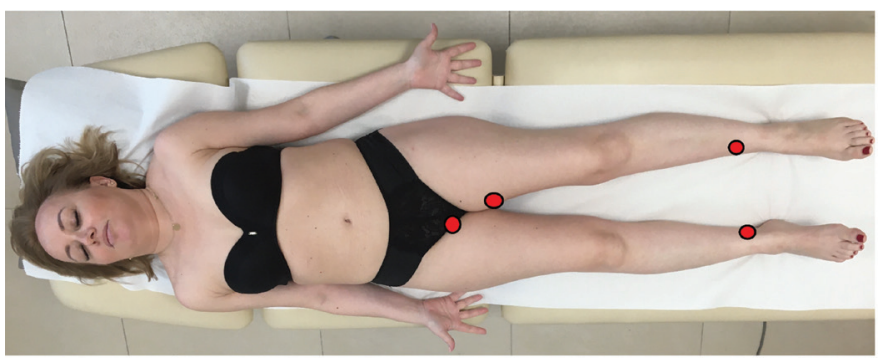

Figure 5. Photo of anteriorpoints. ANMECX rt (the groin) ANMETA2 rt (calf), MECX It (thight), ANMETA1 It (calf)

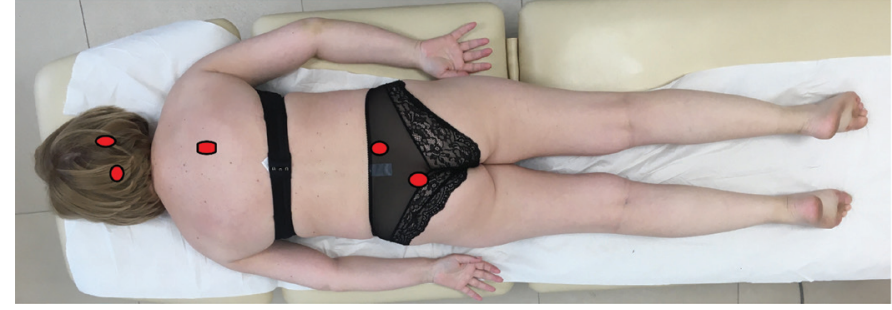

Figure 6. Photo of posterior points. REMECP3 rt, RECP3 It (head), REMETH2 rt (chest), REMEPV1 rt (sacrum), REMECX It (coccyx)

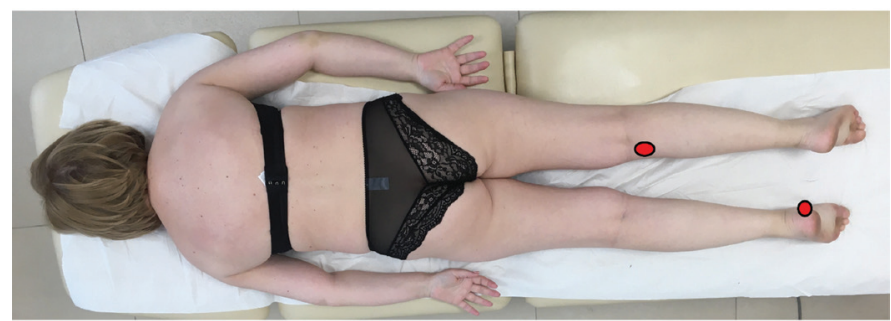

Figure 7. Photo of posterior points. REMEGE2 rt (blowe the knee) REMEPE2 It (foot)

treatment of disorders after episiotomy depending on the three phases of tissue healing. Wound healing is divided into continuous and overlapping phases including coagulation, inflammatory response phase (the first 48-72 $\mathrm{h}$ after the injury); proliferation phase that includes the formation of extracellular matrix (ECM), angiogenesis and re-epithelization (days 4-21); and final remodeling or maturation phase, which may last up to a year. ${ }^{6-9}$ This final regeneration phase results in the formation of a scar with excess collagen and an absence of cutaneous fat and hair follicles. ${ }^{10}$ Fibrillar collagen, as a main structural component of the ECM, has a crucial role both in the elasticity and the strength of an intact skin and scar tissue. ${ }^{11}$ Both normal and pathological scars are the result of deposition of collagen type I and III, although collagen synthesis in hypertrophic scars is two to three times as much as in normotrophic scars. ${ }^{12}$ Collagen III increases more than type I in the early stages of wound healing but decreases during maturation phase to normal levels. ${ }^{13}$

The approach to treatment and its goals should be set out for the individual patient, based upon scar evaluation, patient's characteristics, and expectations in order to reduce the scar volume, minimize subjective symptoms, i.e., pain and pruritus, and to improve function and esthetic appearance.

\section{Inflammatory, coagulation phase (48-72 h)}

In this phase, in addition to typical wound care procedures, it is recommended to perform deep-fascial therapy at the level 
of the pelvis segment away from the wound site. The choice of points for therapy depends on the palpation. The therapist selects the most altered tensile structure (anteroposterior, lateral or oblique) and manipulates the densified points from a given tensile structure. The goal of this treatment is to reduce perineal tone and balance pelvic pressure and improve drainage. We treat the points in the front first and then the back of the pelvis.

\section{Proliferation phase (4-21 days)}

In this phase, we work on segments of the trunk and lower limbs, healing so-called catenaries (carrying lines) and further tensors on the lower limbs. The therapist chooses one of the three catenaries and performs treatment once every 5-7 days. We treat one catenary at each session. We perform three treatments depending on patient's needs. After three treatments, in most cases, all abnormal tension in the fascia of the trunk and extremities should disappear. If there are complications such as lower limb edema, the therapist may perform superficial fascia quadrant therapies directed at the superficial lymphatic system.

\section{Remodeling phase (up to one year)}

A patient in this phase is only treated if there are unresolved ailments in the second treatment period or if she has received treatment without treatment of earlier phases. Patients with dyspareunia and the pudendal nerve entrapment are the ones who present most often. If there is a problem with urinary incontinence as a result of a rupture of the perineum, third or fourth degree, we perform treatment of the urinary apparatus according to FM, where the therapist balances the pressure in the pelvis and eliminates the incorrect tension of the fascia from the lower limbs. In the case of sexual disorders, we offer psychogenic system therapy depending on the type of dominant germ layer. Ectodermal layer requires treatment of the superficial fascia in quadrants of the whole body. Mesodermal layer requires treatment of deep muscular fascia of the whole body and endodermal layer requires treatment of the digestive tract through a deep fascia with catenary.

The goal of this treatment is to regain normal sensation from receptors in the affected fascia and to balance the autonomic tension. For the purposes of this case report, local work will be shown when there is pudendal nerve entrappment, which causes serious problems at the perineal level. The pudendal nerve may be entrapped in the following places; under the piriformis muscle in the subpiriformis canal, at the passage between the sacro-spinal and sacro-tuberous ligaments; in the Alcock canal; or in the superficial fascia in the terminal area along the ischial-pubic branch. Moreover, neuralgia of the pudendal nerve can cause neuropathic pain of varying severity in the perineum, where pain is defined as intense, sharp, with a burning sensation and sometimes as numbness. In some instances, it can cause a sensation of a foreign body in the anus or vagina (sympathy), these are common presentations. Pain is one-sided or often medial, more intense during the day when sitting or wearing tight clothing. Neuralgia of pudendal nerve is often associated with pelvic sensitization and problems with the urinary system (pollakiuria, dysuria), anorectal dysfunction (dyschezia, increased pain after defecation, or before defecation). Sexual problems are often present (dyspareunia, intolerance of vulvar contact, exacerbation of pain after intercourse, persistent genital arousal).

In order to release the nerve at the buttock level, Stecco proposes the treatment of fascial point associated with the piriformis muscle- ER CX, the point in the deep fibers of the gluteus maximus REME CX and RE CX as shown in Figure 8 and Figure 9.

For the entrapment of the pudendal nerve in the Alcock canal, the author suggests a gentle release of the superficial fascia at the level of the obturator foramen, the quadrant qREME CX, photo on the side of the foramen. For entrapment of nerve in the area of the terminal branches, we treat the quadrant qANME CX along the ischial-pubic branch as shown in Figure 10, Figure 11 and Figure $12 .{ }^{14}$

\section{CONCLUSIONS}

The FM method proposed by Lugio Stecco is a new approach to the treatment of disorders in the myofascial system, which can be effectively used to eliminate disorders after an episiotomy. Disorders that are a consequence of complications following a perineal rupture or poorly healing scar causes can present in varying ways and have multiple origins. The versatility of the FM method allows for fast elimination of disorders and helps to improve quality of life. However, further clinical trials are required to confirm the positive results of the therapeutic effects observed by the authors.

\section{DISCUSSION}

In case of Anna the treatment hypothesis was based on her hormonal problems related to dysmenorrhea and other dysfunctions at the head level reflected in clenching of teeth and necessity of braces. From the FM point of view the oldest changes in the fascial system are assumed to be the cause of compensations developing in the body. Dysmenorrhea arises on account of increased myofascial tension in the pelvic region. Episiotomy scar, also contributes to changes in the pelvic region and to alterations in the myofascial system which could be the source of back pain six months after delivery. Although an 


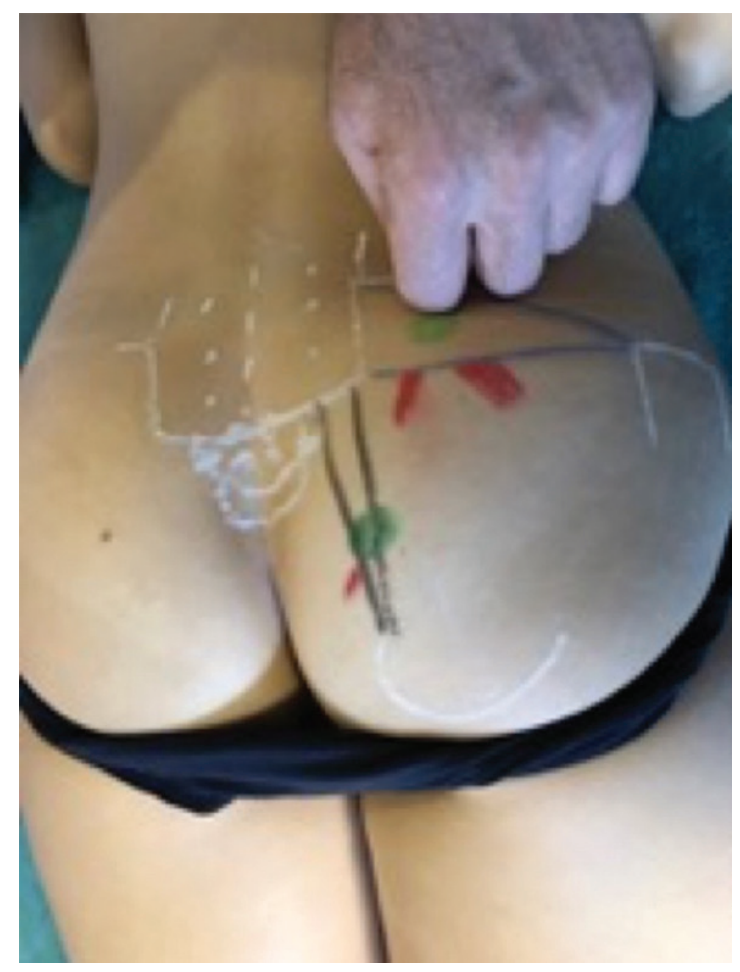

Figure 8. Photo of point at ER CX for release entrapment of the pudendal nerve under piriformis muscle

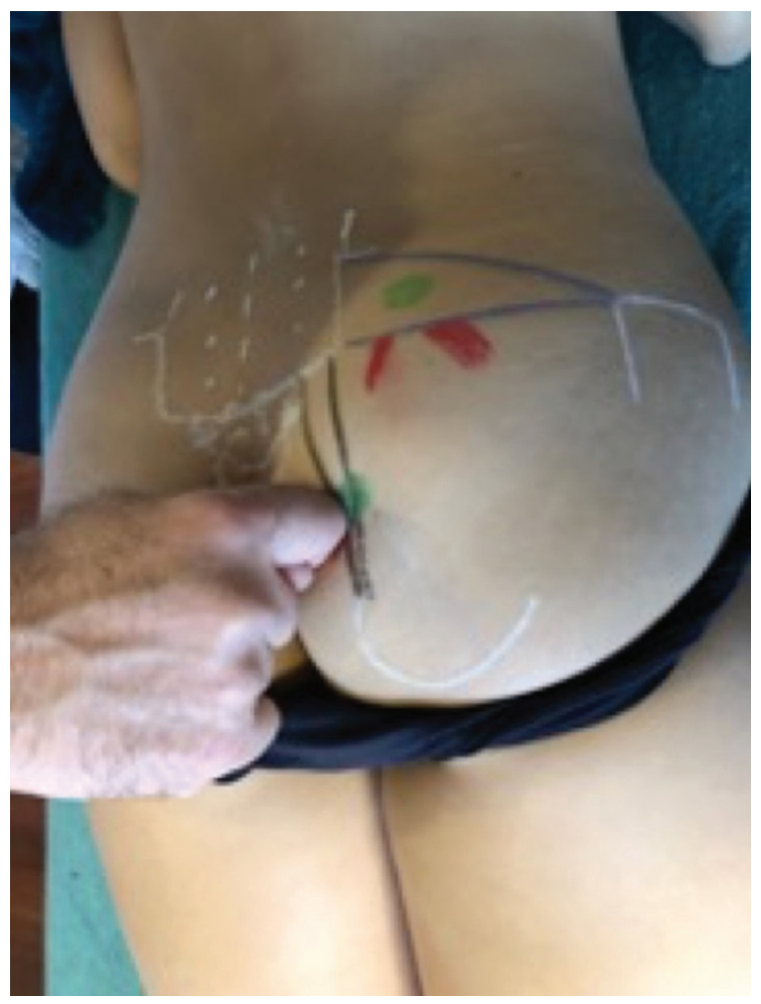

Figure 9. Photo of the treatment of the point of RE CX for release entrapment of the pudendal nerve under sacrotuberous ligament

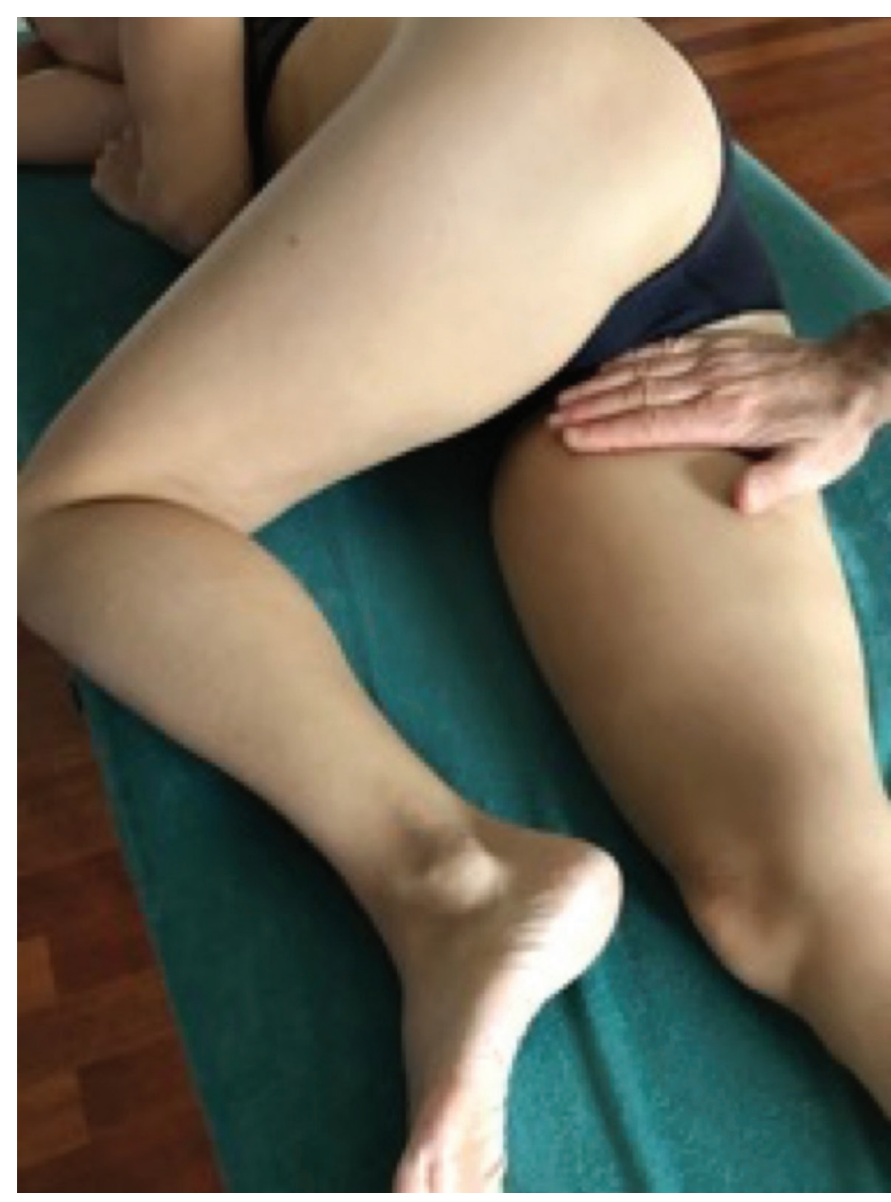

Figure 10. Photo of Quadrant REME-CX for treatment of superficial fascia innervated by pudendal nerve. Treatment focused on branches of pudendal nerve merging from Alcock's canal till the moment of release and restoring gliding between fascial layers

episiotomy scar could be considered as a source of recurrent pain, the treatment always should cover the whole body and be focused on the oldest dysfunction in the body. The principle of "think locally and treat globally" is pertinent to these cases. For this reason, Anna's treatment was global, but also focused on the trauma of the perineum during delivery. It is also worth asking if an episiotomy is a good idea when it may be a potential source of dysfunction and altered myofascial tension. One of the most frequently cited reasons for using a routine episiotomy is to protect the perineum. The question is - how can you protect something while damaging it? An episiotomy corresponds to a second-degree rupture, while women who give birth without an incision most often have a perineum without injury or with a first-degree rupture.

An analysis of 350 medical publications from 1860-1980 carried out in the early 1980s did not confirm any benefits from routine incision in preventing deep perineal injuries of anus, pelvic muscles 


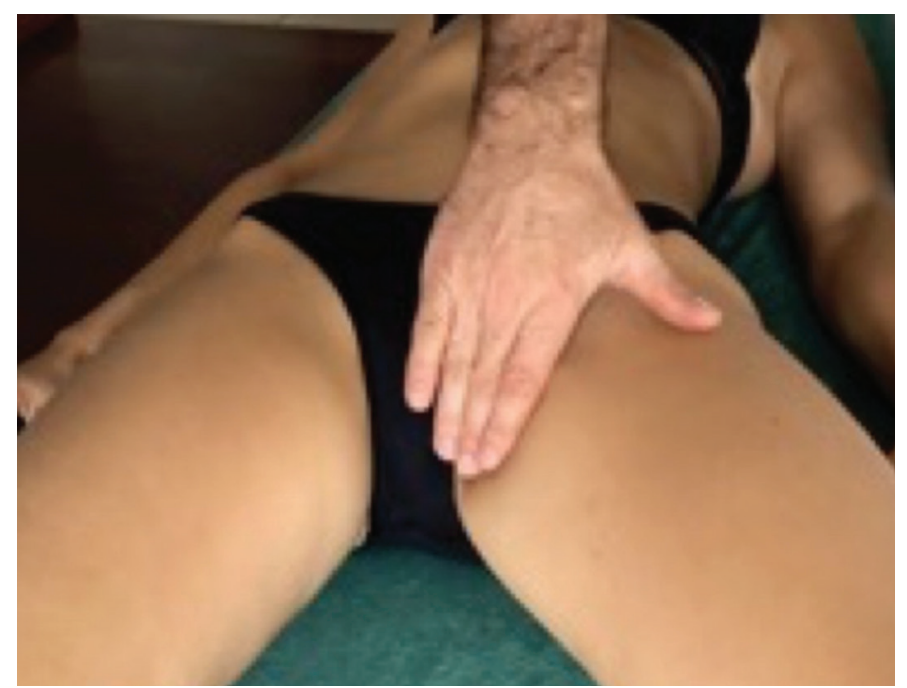

Figure 11. Photo of quadrant ANME-CX for the treatment of superficial fascia and terminal branches of pudendal nerve. Treatment focuses on terminal branches of the nerve via treating of the alteration of superficial fascia consistence till the moment of release and restoring the gliding of fascial layers

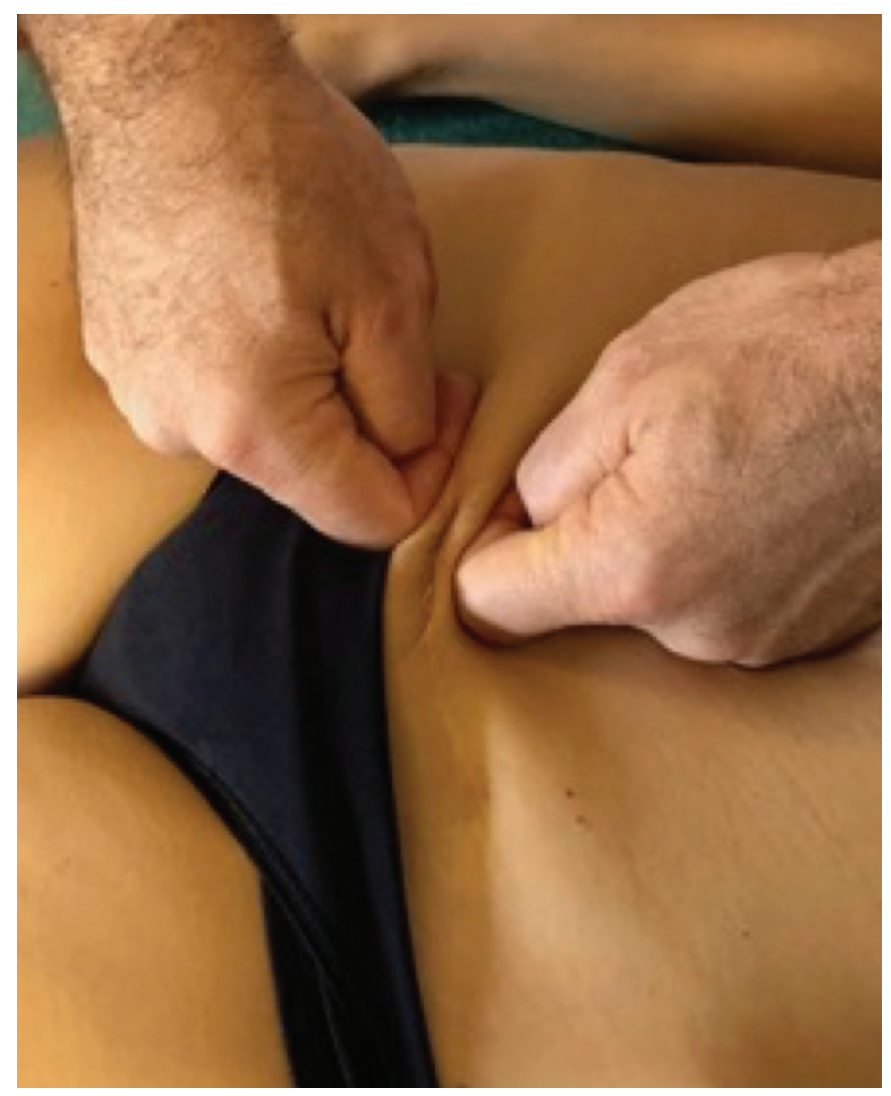

Figure 12. Photo of scar treatment. For the purposes of this article, an example of a scar mobilization is shown by the example of Caesarean section scar. We rub at the site of the altered scar till the moment when the therapist will feel releasing of the tissue or fetal head injuries. ${ }^{15}$ The authors cite a study comparing perineal healing between one and two weeks after delivery in a group of 181 women undergoing episiotomy and in a group of 186 women who did not undergo surgery. All women belonged to the low-risk group, the delivery was natural. Only $2 \%$ of women in the group without episiotomy had grade III and IV tears, compared to $15 \%$ in the group with incision. In the incision group, $7.7 \%$ of women with prolonged perineal healing were reported compared to 2.2\% in the non-incision group. The difference is statistically significant when eliminating women from the incision group who have not suffered from any injury (53\%). In none of the four cases of fourth degree rupture in the group of patients without incision was there prolonged healing. By contrast in the incision group, 27 women had third degree rupture and in 18.5\% there was prolonged healing of the perineum. Furthermore, two infections were noted, both in the perineal incision group.

Other authors mention various negative consequences of routine incision. These include further incision rupture, significant blood loss, dyspareunia (pain during intercourse), perineal soreness, long healing, infections. According to Sarfati et al. ${ }^{16}$, blood loss as a result of an episiotomy is comparable to blood loss by caesarean section. McGuiness et al. ${ }^{17}$ briefly reviewed research showing that an episiotomy does not protect pelvic floor muscle tone, nor does it protect from rapture or harm to the fetus. Instead, it increases the risk of infection, including fetal infections, increases pain and dyspareunia, and also causes significant blood loss. Routine episiotomy does not prevent perineal injuries, pelvic floor muscle damage, organ prolapse or fetal hypoxia. Rather it increases the risk of third and fourth degree tears, infection, prolonged wound healing, prolonged dyspareunia and perineal pain and sexual disorders such as lack of interest in sex or lack of an orgasm.

Perineal care after delivery should be a routine procedure regardless of whether the perineum has been injured or not and there are a few rules to follow. Before fetal placenta delivery, it is worth asking a woman to do a series of Kegel exercises. Rhythmic muscle contractions are a good start for regeneration processes and maintaining the elasticity of tissues stretched during delivery. During the puerperium, a woman should avoid any lifting of weights (i.e. a tub filled with water or shopping bags). Patient should also avoid doing housework that requires long periods of leaning, such as vacuuming carpets. Failure to follow these guidelines can have serious consequences - the pelvic muscles and ligaments of the uterus may never return to their former elasticity - causing ailments attributed to births such as lowering of the reproductive organ and incontinence. It is worth remembering that, doing regular Kegel exercises after delivery restores elasticity to tissues stretched during pregnancy. 
Care of the incised or torn perineum should be an important aspect of postnatal care. It is good for patients to remember that panty liners should be cotton as those with a mesh surface cause painful burns and healing problems. Pads should change frequently. The wound should be well ventilated and a hair dryer used to dry the area after bathing. After each urination and stool, wash the perineum with water without cleaning agents. If the perineum is swollen, apply cold compresses. For washing and rinsing perineum during the healing process, you can use: infusion of calendula, oak bark or arnica, lavender oil (three drops of oil dissolved in a small amount of milk and one liter of water), tea oil (a few drops per three liters of water), Szostakowski lotion or Tantum Rosa solution (these can be bought in sachets at the pharmacy). If the wound was painful and is not healing well, it is worth rinse it with $10 \% \mathrm{NaCl}$. Avoid hip baths as they can accelerate the dissolution of stiches. Arnica five or nine $\mathrm{CH}$ (five granules three times a day) should be used as a homeopathic remedies during this period.

\section{DISCLOSURES}

The authors declare no conflict of interest, and no financial support by any grant or research sponsor.

Peer-review: Externally peer-reviewed.

\section{REFERENCES}

1. WHO 1997, Care in normal birth: report of the technical working group, WHO/FRH/MSM/96.24, 1913.

2. WHO, Poród nie jest chorobą, 1985.

3. Delie JB. Principles and Practices of Obstetrics, W.B.Saunders, Philadelphia

4. Enkin M, Keirse M, Neilson J, et al. A Guide to Effective Care in Pregnancy and Childbirth. Oxford University Press, 2000.
5. Wagner M. Pursuing the birth machine, The Search for Appropriate Birth Technology. ACE Graphics, Camperdown, 1994.

6. Li J, Chen J, Kirsner R. Pathophysiology of acute wound healing. Clin Drematol 2007; 25: 9-18.

7. Xue M, Jackson CJ. Extradellular matrix reorganization during wound healing and its impact on abnormal scarring. Adv Wound Care (New Rochelle) 2015; 4: 119-36.

8. Stecco C, Stern R, Porzionato A, et al. Hyaluronan within fascia in the etiology of myofascial pain. Surg Radiol Anat 2011; 33: 891-6.

9. Matteini P, Dei L, Carreti E, Volpi N, Goti A, Pini R. Structural behavior of highly concentrated hyaluronan. Biomacromolecules. 2009; 10 : 1516-22.

10. Borthwick LA, Wynn TA, Fisher AJ. Cytokine mediated tissue fibrosis. Biochim Biophys Acta 2013; 1832: 1049-60.

11. Kadler KE, Holmes DF, Trotter JA, Chapman JA. Collagen fibril formation. Biochem J 1996; 316: 1-11.

12. Linares HA, Kischer CW, Dobrkovsky M, Larson DL. The histiotypic organization of the hypertrophic scar in humans. J Invest Dermatol 1972; 59: 323-31.

13. Gay S, Vijanto J, Raekallio J, Penttinen R. Collagen types in early phases of wound healing in children. Acta Chir Scand 1977; 144: 205-11.

14. Stecco L, Stecco A. Fascial Manipulation for Internal Dysfunction, Practical Part. Piccin, 2016; 248-57

15. Thacker S, Banta HD. Benefits and risks of episiotomy: an interpretive review of the English language literature, 1860-1980. Obstet Genecol Survey 1983; 38: 322-38.

16. Sarfati R, Marechaud M, Magnin G. Comparison of blood loss during cesarean section and during vaginal delivery with episiotomy. J Gynecol Obstet Biol Reprod (Paris) 1999; 28: 48-54.

17. McGuiness M, Norr K, Nacion, K. Comparison betweeen different perineal outcomes on tissues healing. J Nurse Midwifery 1991; 36: 192-8. 